O presente artigo propõe-se a disatirir odispositivo de tratamento institucional, por meio do estudo de um caso atendido na Pré-Escola Terapêutica Lugar de Vida. Para tal, o questionamento sobre a constituição do sujeito na criança, a posição subjetiva da criança no disarso dos pais e a constituição do Outro para a criança foram articuladores centrais para a leitura do caso. Pretende-se tambématravés da escrita do caso transcrever o que é da ordem do Real na clínica das psicoses para una inscriçãopossível no que é da ordem do autro e para o autro. É a partirda clínica enaclínica, indagandb o sujeito em questão que o sujeito-agente-interventor do tratamento colocará também em evidência sua própria posição e seu assujeitamento diante do não-Saber.

Caso clínico; constiturição do sujeito; constituição do autro; tratamento institucional

FROM THE UNFEASIBLE SEPARATION TO THE OTHER POSSIBLE TREATMENT... THE CHILD QUESTION THE TREATMENT

This text suggests, thragh the study of a case attended at Iugar de Vida Therapeutics Pre-School, to inquireas a last resort, the self-medanigmof the institutio nal treatment. Aiming that, questions abat a child's subject of constitution, hersibjectiveposition in her parent's speech and the construction of the ather to her, were themainartiaulators to its reading. It is also intended, through the written text from the case, to transcribe what is fran the Real order in the clinic of psychoses for a feasible inscription of the Other's order and what is for the other. It is from the clinicandin the clinic, questioning thesbject inmatter, that the acting subject of the treatment will also put in evidende his self-position andhis submission in face of the 'unknoun'. Clinic case; stbject's constitution; the Other's constitution; institutional treatment

\section{DA SEPARAÇÃO IMPOSSÍVEL AO \\ TRATAMENTO DO OUTRO POSSÍVEL... \\ A CRIANÇA INDAGA \\ O TRATAMENTO}

Cristina Keiko Inafuku
O HISTÓRICO DO DESENVOLVIMENTO

Y bro de 2001, com oito anos, tranças adomadas com coloridas fivelas e uma enorme e assustadora boca, aos berros. A principal queixa trazida pelos pais éa de que não fala e tem crises. Quais crises? Y. berra e bate a cabeça na parede quando fica nervosa ou quando recebe um não. Seus pais temem que essas crises desencadeiem uma convulsão. Do Hospital das Clínicas, vem com o diagnóstico psiquiátrico de G40 + F72 (epilepsia e retardo mental grave) .

Do ponto de vista orgânico, Y. é uma criança bastante investigada: exames de eletroencefalograma, tomografia, audiometria e genética, toolas com resultados normais. Até os quatro meses era uma criança dita normal, ativa, sorridente e firme. Por

Psicanalista, membro da equipe da Pré-Escola Terapêutica Lugar de Vida - USP. 
volta dos cinco meses, começa a apresentar refluxos, ficando com a boca roxa e extremidades do conpo frias. Toma-se um bebê "molinho" e desconectado. Mbria, a mãe, relata as situaçães de refluxo com muita angústia e desespero. Não sabia o que fazer: chorava, enrolava Y. no cobertor e a abraçava para aquecê-la. Paralisada, não conseguia dirigir-Ihe nenhuma palavra.

Aos sete meses, ainda era um bebê mole demais; não sentava e não sustentava a cabeça. Engatinhou com um ano e andou com três, quando então começau a reconhecer mais as pais. Antes, era indiferente à presença deles e de autras pessoas. Usau fraldas até seis anos. Em julho de 2000, foi avaliada em clínica neurológica de convênio particular, faz exame de cariótipo e tomografia de crânio. O relatório médico indicou atraso no DNPM (desenvolvimento neuropsicomotor) e registrou uma "pequena" observação: criança sem condições de freqüentar escola nomal. Segundb as pais, os médicos disseram que havia uma pequena mancha no cérebro, que poderia sumir com o tempo, e que seria provavelmente devido à "geração" (fala da mãe referindo-se à gestação) . O psiquiatra do mesmo convênio receitara Neuleptil e Pasal ix para acalmar e dormir melhor à noite; a mãe, no entanto, não aceitara a medicação por discordar da conduta médica, "ele nem olhou paraela".

\section{O SIGNIFICANTE DO NOME YOLANDA E O CASAL PARENTAL}

O nome Y. foi escolhido pelo pai, nome de uma personagem de novela, mulher poderosa e autoritária que comandava uma grande empresa. Fm casa, Y. se apossava dos controles das duas televisões e impedia aas berros que os demais assistissem a qualquer outro programa. Por esse motivo, na discussão interna da equipe de triagem, o caso foi batizado de "Yolanda-manda" : não comandava uma grande empresa, mas mandava e desmandava em uma casa inteira.

Y. nasceu num ano de muitas discussões entre o casal que, naquele momento, pensava em se separar. Segundo os pais, após o nascimento de Y. , pararam de brigar; diziam que era como se Deus tivesse mandado uma bênção. Pode-se pensar que, no discurso dos pais, Y. viera ocupar o lugar de uma oferenda, um Messias com uma missão a cumprir: apaziguar as brigas de seus pais. Estes, por sua vez, retribuem, satisfazendo-a em todos as seus desejos. Nesse momento, Y. acaba ocupando para seus pais o lugar de representante imaginário do grande autro, que dita as 
regras da família e diante do qual têm que se curvar e calar. De qualquer modo, Y. vem para calar não só as brigas, mas, com seus berros, calar tambéma fala dos pais. Estes, então, nada têm a dizer sobre sua filha; nada sabem sobre ela e esperam dos profissionais toob o saber.

O LUGAR DO PAI E A FUNÇÃO PATERNA

A gravidez de Y. foi marcada, na história da mãe, pela morte de seu pai, homem alcoólatra que, tentando evitar o estupro de uma adolescente, na valentia de sua embriaguez acabou sendo esfaqueado pelo agressor. No relato matemo, também há uma referência ao avô paterno de Y., homem igualmente alcoólatra, com crises de epilepsia que 0 impediam de trabalhar. Por sua vez, o pai de Y., filho mais velho e único homem entre quatro irmãs, desde cedo assumiu as despesas e responsabilidades da casa. M. se queixa de que $C$. sempre foi mais filho em sua família de origem do que pai na família que constituiu com ela. Refere-se ao marido como homem muito fechado e tímido, assim como ela, e um pai sem paciência e firmeza com os fiIhos, pois, por não agüentar os berros de Y. , sempre acaba cedendo aos desejos dela. Diz ele <eeu fico agoniadb, não sei o que fazer; aí dou logo o que ela quer para parar de berrars>. Esse pai, diante do horrore da paral isia matema frente à criança, responde também com sua impaciência e impotência em ampa- 
rá-las. Quando Y. tinha três meses, o pai decidiu fazer vasectomia. <«Já tínhamas conseguido um casal e por $Y$. ter vindo com problemas, achei melhor eu fazer a cinurgia, também porque minha mulher sofria com os anticoncepcionais >>... < <lepoois que a Y. nasceu, só nos preocupávamos com a saúde dela. Eu nem tinha mais tempo ou disposição para pensar em querer e fazer mais fithos >. Comessa decisão, sela também em seu conpo o que imaginariamente poderia dar sustentação a um lugar fálico. A partir do nascimento de $Y$. , o casal une-se fratemalmente nos cuidados com a criança doente, ficando no esquecimento ou na indisposição o casal sexul.

Interessante e ao mesmo tempo desanimador notarmos também o significante do nome do pai de Y. (reserva-se a não citação do nome) . Como se não bastasse a posição de clemência, junta-se a ela o lugar de cordeiro, duplamente resignado. Refere a si mesmo com as seguintes afirmaçães: <<Fico muito angustiadb com os berros da $Y$.; não sei mesmo o que fazer. Falar não adianta, bater também não. Aí não agüento e tenho que chamar a mãe dela. Então me afasto>>. Podemos imaginar o referencial fáliconessa fanúlia, apontando para uma fragilidade, antes de afirmar precipitadamente a não existência de um Nome-do-Pai.

\section{A FUNÇÃO MATERNA}

Ao retomarmos a primeira infância, nos relatos das primeiras relações entre Y. e sua mãe, verifica- mos que já na própria amamentação, o terror e a paralisia matema diante da criança se fazem presentes. Laznik (1997) faz consideraçães importantes sobre esse primeiro tempo da relação mãe-bebê, apontandb o olhar matemo sobre a criança como fator fundante de sua imagem conporal. A mãe, por seu olhar, oferece ao bebê uma ilusão antecipadora de sua imagem.

Podemos pensar que, no caso de Y., não se trata da ausência ou recusa do olhar matemo, mas de um olhar aterrorizado, cuja fantasia, produzida a partir de sua conduta, parece ser "ela tem frio, ela vomita, ela pode morrer" . A partir daí, passa a lhe dirigir um excesso de olhare excessso de presença com a seguinte atuação <<tenho que aquecê-la, tenho que socorrê-la, não posso ficar lange delass.

Então, pensemos, por que em Y. sua unidade conporal é tão fragilmente constituída e a vivência do despedaçamento se faz tão presente em seu corpo? Para responder a esta questão retomemos outra proposição de Laznik (1994) , o circuito pulsional e os três tempos da pulsão. No caso em questão, $03^{\circ}$ tempo da pulsão merece destaque. Esse tempo se refere ao tempo passivo do bebê, no sentido de que ele se faz objeto de um outro, porém trata-se de uma passividade aparente, pois nesse assujeitamento ao outro ele ativamente pretende se enganchare $e$ ser enganchado no gozo do Outro.

No caso de Y., pensamos que "b se fazer dbjeto", a oferta dos objetos a de seu conpo ao gozo matemo, por condições ou restrições de ordem também orgânica, foram ofer- 
tas bastante restritas; as vônitos e sua borda - a boca - circunscreveram um lugar particular de gozo, enlaçando-se libidinalmente à mãe mesmo que de forma terrorífica. Assim, pode-se dizer que o tempo da al ienação foi de algum modo alcançado, mas este assujeitamento ao attro teve sua particularidade, e as pulsões em jogo foram bastante parciais; arriscamos propor pensar em uma "alienação parcial", falhada, bem como um modo muito partiallar e fixo de gozo.

En trabalhos mais recentes Laznik (2000) muda o foco do ol har matemo para a voz matema. Afirma que é uma invocação de uma voz portadora de uma prosódia particular, um modo especial, melodioso da mãe falar a seu bebê que capturará a sua atenção, antes mesmo do olhar. Confere à voz o lugar de primeiro abjeto da pulsão oral, os picos prosódicos como primeiros objetos dessa pulsão; algo do desejo da mãe sobre a criança seria também traduzido pelos traços acústicos e que têm seu eixo nos modos prosódicos da fala dos pais. O recém-nascido olharia para sua mãe, grande Outro primordial de sua vida, a partir da experiência da prosódia da voz matema, a qual lhe possibilitaria identificar sua presença como objeto-causa de um gozo desse Outro primordial. Ele vai procurar então o rosto que corresponde a essa voz particular, fazendo-se objeto desse olhar também gozozo. A voz e o olhar matemo se articulariam para a formação de um circuito pulsional escópico. Antes mesmo da experiência da satisfação alimentar, o recém-nascido teria uma apetência extraordinária para o gozo que a visão de sua presença desencadeia no Outro materno. Antes mesmo do leite, o bebê demonstra apetite por palavras especiais, palavras alimentadoras.

No caso de Y. , lembrando seus primeiros meses de vida, verificase que algo do olhar matemo foi tomado como traço, algo da ordem do estarrecimento em seu rosto; porém o que parece ter ficado ausente nesta relação foi justamente a prosódia da voz matema: < <eu ficava tão assustada com os vônitos que não conseguia falar nada, só a abraçava e a aquecià>. Não nos parece à toa que Y. , agora em tratamento, diante da convocação e da entonação na voz do Outro freqüentemente vá para o espelho e, estarrecida diante de sua própria imagem, abra a enorme boca-buraco e solte o que de mais real a voz pode portar: seus berros, urros, o puro grito. Pensemos então, será que Y. poderá em algum momento transformar o grito em apelo?

\section{SOBREDETERMINAÇÕES}

Y. com sua boca-borda, lugar de gozo, no lugar dos vômitos da primeira infância, primeira oferta e ao mesmo tempo recusa à sua mãe, oferta-lhe hoje em sua adolescência os berros, o xixi e seu sangue menstnual, abjetos residuais. M. , por sua vez, novamente responde à fi tha com seu terror e paralisia diante da sexialidade e do mortífero que Y. encarna neste momento, lugar mesmo de dojeto a S1's que se repetem e cujo 
enodamento é na ausência, no vazio de um S2, pois sua mãe novamente se cala diante deles. Diante do xixi que Y. passa a fazer nas calças, durante o atendimento de grupo, na mesma época em que menstrua pela primeira vez, o profissional referência pergunta à mãe se conversou com a fil lha sobre a menarca e como se refere ao órgão sexual feminino. M. responde que apenas mostrou como se trocava o absorvente, como deveria fazer para limpar-se, mas não conseguiu nomear o genital feminino, nem lhe explicar nada. Parece-nos que novamente M. não conseguiu dar contorno simbólico ao que no real aparece como buraco: <<ah, não tem nome, não falo para ela > ... <<sóme preocupo que agora, mocinha, a gente tenha que cuidar mais, não pode ficar muito com os moleques >>. (Lembremos que, na história da mãe, há uma significação especial entre a morte de seu pai e o estupro de uma adolescente). Sobre essa questão Al fredo Jerusal insky dbserva em supervisão institucional do caso (2003) que a mãe reencontra de modo sinistro, na adblescência de sua fi lha, o que fabricau em seu fantasma, relação antitética do desejo em relação ao fantasma, gozando sempre na esperança de não encontrá-lo, afirmando tratar-se mais de uma sobredeterminação do que de uma reedição edípica na menina que entra na adblescência.

Lacan (1955) faz uma releitura sobre o texto de Freud (Mais além do princípio do prazer) assinalandb a questão da repetição, de uma insistência repetitiva significativa, na qual o instinto de morte opera como propulsor de toobs as sintomas repetitivas, do desejo infinito, multiforme. O desejo assim, se satisfaz em autra parte e não em uma satisfação efetiva, é a própria fonte, é a introoução fundamental do fantasma como tal. Trata-se de algo que está além do drama, trata-se de uma identificação entre essa preterição velada e a morte, em seu aspecto mais horrível.

Ainda sobre a questão da sobredeterminação, Lemer (2004) apresenta em sua pesquisa mais formulações de Jerusalinsky em supervisão de seu trabalho. Algo que poderia não causar nada em um sujeito, ao tomá-lo pela incidência de autros processos, pode se transformar numa causa, já que transforma sua significação e isso é o que chamou de sobredeterminação. Uma determinação inconsciente, que poderia não causar absolutamente nada em um sujeito qualquer, em outro, transforma-se em causa de uma perturbação, justamente porque sua significação vai depender de um texto e de uma determinada pasição neste texto. Por isso refere-se também a Lacan, tomando a questão da letra no inconsciente, numa posição contextual e textual que o sujeito já encontra ao nascer. A clínica registra que o modo de incidência de elementos patológicos registrados na genética e na neurologia é muito variável no que diz respeito aos processos psíquicos e que essa variabilida- 
de depende justamente do modo como eles aparecem sobredeterminados; eles não atuam isoladamente. As relações entre a genética e a maturação neurológica com a matriz psíquica e a matriz cultural mostram-se extremamente relevantes e inseridas nos princípios da sobredeterminação.

À luz do caso atendido, lembrando o refluxo do bebê como evento significativo e fundante da relação que se estabeleceu entre Y. e sua mãe, do buraco-boca para o buraco-vagina sem contomos simbólicos, das determinações orgânicas, psíquicas, contextuais e das determinações significantes no disarso familiar, podemos afirmar que acabaram por promover o encontro dessa mãe com o que de resto, de dbjeto a, a criança pôde portar de seu fantasma; isto nos leva a pensar que deve haver muitas determinações para que um sujeito encontre o que para sempre deveria estar perdido em seu fantasma. Trata-se mesmo da sobredeterminação.

O GRANDE OUTRO ABSOLUTO E A SEPARAÇÃO IMPOSSÍVEL

O significante "geração" na fala da mãe traz à tona o que é da ordem da filiação. M. desejava muito ter uma menina, pois já tinha um primeiro menino e esperava uma filha para the fazer companhia. No que diz respeito às gerações anteriores, as semelhanças entre o casal de avós patemos e matemos chamam a atenção. Ambos os avôs sofreram de al- 
coolismo, eram homens dependentes e impotentes. As avós, por atro lado, mulheres autoritárias e controladoras que rivalizavam entre si. Y. parece encamar não só a companheira inseparável da mãe, mas aquela que manda e desmanda com seus berros, a lém de representar a oferenda que veio calar as brigas de seus pais. Dolto (1972) já dizia que eram necessárias três geraçães para produzir uma psicose. Não nos parece mesmo um excesso de Outro? Outro diante do qual Y. parece tomar-se prisioneira.

M. por sua vez, oscila entre a posição "nada sei sobre minha fi lha" e "só eu sei como fazer quando ela tem crises". De um modo ou de outro, essa mãe representa um Outro absoluto, au tuob au nada, a falta significante e a flexibilidade disarsiva na mãe ficam bastante comprometidas. Y. parece constituir para si um grande Outro não-barrado, invasivo e ameaçador diante do qual recome a três principais defesas. Ora fragmenta-se, respondendo esquizofrenicamente com seu conpo aos pedaços, ora anula-se numa fuga autística. Emuma terceira tentativa, um pouco de Outro se toma possível para ela, em construções e jogos miméticas e delirantes.

Colette Soler (1997) propõe pensar a psicose no fora do discurso, numa instalação no campo da alienação e na não operação da separação, condicionada pelo Nomedo-Pai. o atro caracterizaria, portanto, um Outro não-barrado, de gozo absoluto, que sem a simbolização primordial da presença/ausência, da instauração da falta, permanece para o sujeito como puramen- te real. Por sua vez, a criança em questão permanece puro significado do outro. A partir dessa formulação é que chega à questão da separação: a criança não pode se separar do Outro porque o Outro não é o objeto que compense imaginariamente sua falta, mas sim uma parte de sua libido. Se ela se separa, seu compo cai, inerte.

Em Y. podemos verificar a adesividade e o aprisionamento ao grande outro primordial. Apesar do sofrimento, estando à mercê do gozo absoluto e terrorífico de sua mãe, sem ele o que the restaria? Com freqüência nos deparamos com esse encontro sujeito-criança e Outromãe em enlace libidinal de puro gozo, em que a entrada de um terceiro, de uma intervenção no tratamento toma-se extremamente difialltada e refratada. Talvez por isso possamos pensar agora que uma intervenção muito incisiva, abrupta, de corte visceral, nesses casos não seja possivel, estrategicamente para sustentar o tratamento, pois corremos - risco de acionar na mãe uma posição de grande resistência ou abandono e na criança uma queda sem nenhum amparo.

\section{O TRATAMENTO - AS INTERVENÇÕES - $1^{\circ}$ MOMENTO: O JOGO DO ESPELHO}

Passemos então ao que Y. pôde nos dizer no decorrer do tratamento. Nos primeiros encontros, nos deparamos com uma menina que apresentava um repertório de jogos 
e brincadeiras. Tratava-se no entanto de jogos bastante solitários: fantoches que falavam sonoplasticamente entre si, livros e fitas de vídeo que enfileirava sobre a janela, coreografias e múmicas representadas só e insistentemente para o espelho. 0 outro, nesse momento, servia somente como uma mão a mais para sustentar um fantoche, um personagem a mais para ser olhado através do espelho e um intruso, caso este tocasse em um livro da janela. O outro era tomado como mera extensão de si e, quando este sustentava algum desejo, demandando-Ihe algo, tomava-se extremamente invasivo, provocando reações em Y. : a cabeça sendo martelada no chão e a assustadbra boca aberta aos berros, que silenciava qualquer attra fala e fazia cair por terra qualquer intervenção. Essa cena lida fencmenologicamente pode facilmente levar o profissional a diagnosticá-la prontamente como autista.

Lembremos Lacan (1949) em O estádio do espelho camo formador da função do eu no qual esclarece que a constituição da imagem corporal do sujeito se dá por um drama cujo "impulso interno precipita-se da insuficiência para a antecipação e que fabrica para o sujeito, apanhado no engodo da identificação espacial, as fantasias que se sucedem desde uma imagem despedaçada do corpo até uma forma de sua totalidade" (1998, p.100) . Com relação a Y., podemos supor que ela viva ainda constantemente esse drama, numa tentativa de juntar os esti lhaços de um espelho que sequer havia sido constituído inteiramente. 
Vejamos, então, de que modo o jogo especular permite a constnução, neste caso, de uma imagem corporal mais integrada.

\section{$2^{\circ}$ MOMENTO: A \\ POSSIBILIDADE DE UM \\ OUTRO}

Num segundo momento, já decorrido cerca de um ano de tratamento, nota-se que Y. passa a necessitar menos do espelho para incluir o outro em suas performances. Vínhamos sustentando no grupo que, para nos incluir, ela também poderia sair do espelho e nos chamar. Aos poucos, Y. passa a se dirigir não somente aos adultos do grupo, mas também às outras crianças, puxando-nos, dando-nos as mãos, pedindo para abraçá-la ao representar uma princesa desmaiando no atelier de Contar Histórias, dizendo "Ai, socorro!". Esta é uma das ofertas que a montagem grupal institucional do Lugar de Vida proporciona às crianças em tratamento, que lhes possibilitita o encontro com os contos da cultura bem como o encontro com suas próprias histórias (Teperman, D. e Inafuku, C. K., 1996) .

Lembremos Alfredo Jerusalinsky, em $A$ formação da imagem conporal, de 1991, verificando que numa criança pouco estruturada, o sentido muitas vezes falta à ação. Um "bebê recolhe religiosamente, minuciosamente, cada traço, cada marca, cada emissão de voz matema, cada letra e cada gesto e os solda ao redor de cada buraco que nele se manifesta com substância gozante" (p. 127) , numa tentativa de articular um domínio desse boneco esquartejado, que é o conpo inicialmente. Essas qperaçães fixam um significante no real, em que "o sujeito abre as vias de imaginarização de seu conpo que se oferece, assim, ao olhar do outro. É para o outro que a nossa imagem no espelho se organiza, e é de seu olhar que imaginamos o que somos enquanto corpo" (p. 132) . No atelier de Contar Histórias, imersos todos no imaginário mundo das contos de fadas, sob um Outro da Cultura, menos demandante e menos invasivo, um pouco de princesa foi possível ofertar a essa menina, que mais freqüentemente lembra a boca de um terrível dragão.

\section{INTERVENÇÕES NA FALA}

A fala de Y. também sofreu alterações importantes, que foram mais observáveis no segundo ano de tratamento. A sonoplastia de um desenho animado incessante começa a ter escansões e entonações diferentes. Algumas palavras passam a ser destacadas mais claramente: 0 "ou" = não; "dada"; "tau" = tchau; socorro, mamãe; "rm-dois e chá". Não nos surpreende que ainda não tenha conseguido chegar no três. Apesar de poucas e mal articuladas palavras, é interessante notarmos como elas estão sendb utilizadas por Y. numa linguagem bastante peculiar. Rosine e Robert Lefort (1991) consideram o autismo como estrutura não definida, a partir da qual é 
possível desenvolver uma psicose paranóica ou uma debilidade. Esses autores afirmam que, nessa organização psíquica, por mais mudo que o indivíduo seja, ele está na linguagem, sem ter entrado no discurso. Ele não se dirige ao outro, não acede ao símbolo; permanece petrificado no nível do S1 sem S2, em um real dificilmente simbolizável, objeto diante de um outro absoluto. No caso de Y., podemos pensar que há palavras que adquirem certo valor significante (preservandb o que se considera literalmente como significante) , com uma extensão e flexibilidade que estão longe de configurar uma cadeia ou rede. Operam como signos, mas apesar de sua fixidez, cumprem uma função de enlace com o Outro e uma pequena ponte para o discurso do outro. Talvez caiba aos interventores pensar se, diante de uma linguagem tão pouco flexível, a flexibilidade deva então existir justamente no discurso do Outro.

É interessante doservar como Y. inconporou a palavra "hão" . Num primeiro momento, era diante do "não" do outro que Y. parecia se despedaçar. Atirava-se ao chão, debatia-se e a única parte do corpo que se fazia presente era sua boca enorme e megafônica ecoando o "dadá" seguido das cabeçadas. Num segundo momento, ela mesma passava a ecoar a fala "não" do outro, repetindo a mesma seqüência. E mais recentemente, diante de nosso "não", imediatamente dirige seu olhar, o que raramente faz quando the demandamos algo mais diretamente, e responde em tom de indagação "ou?", nem sempre seguida da seqüência citada. Parece conter-se apenas chorando e batendo os pés no chão ou simplesmente parando com o que a impediram de fazer. Recentemente, outra seqüência se segue a esta. Em situaçães de restrições e limites, Y. olha para o adulto e faz "tsu-tsu" balançando a cabeça negativamente. Quando dizemos "não", ela desencadeia os berros, cabeçadas e ataques a outro; por outro lado, quando não proferimos o "não", encara-nos em uma espera suplicante pelo dito-interdito que a leva ao encontro sofrível com o gozo do Outro. Em uma direção mais recente do tratamento, no lugar do dito-interdito, temos oferecido a Y. autras possibilidades, diante das quais, apazigua-se e, aos poucos, consegue prosseguir brincando.

\section{O ENLACE COM O OUTRO E O TRATAMENTO DO OUTRO}

O acompanhamento das seqüências produzidas por Y. serviu para pensar nossas intervenções. Não se trata de não susten- 
tarmos o interdito. Mas é preciso que nós mesmos, representantes do grande Outro, também estejamos submetidos, barrados por esse Outro e que não encamemos esse Outro tão assustador, absoluto e inflexível para esse sujeito (como o faz sua mãe - grande autro primordial) . Talvez essa qperação possibi lite que Y. não goze desse autro, ao verificar que o autro, que é veículo do interdito, tambémé faltante, não é absoluto, e talvez para ela, então, mais tolerante e menos invasivo. É certo que essas situações oscilam, mas parecem caracterizar novas construções em Y., as quais põem também em construção as intervenções e a posição do profissicnal - analista - interventor.

Sobre a questão das intervenções e dos tratamentos analíticos institucionais, Alfredo Zenoni afirma: "antes mesmo de visar tratar o sujeito, a instituição existe para acolhê-lo; antes de ter um dojetivo terapêutico, ela é uma necessidade social. É a necessidade de uma resposta aos fenômenos clínicos, a certos estados da psicose, certas passagens ao ato, certos estados de deteriorização psíquicos que podem conduzir o sujeito à exclusão social absoluta ou à morte que motiva a criação de uma instituição" (2002, p. 3) . Afirma que é por causa de algo clinicamente insuportável, quando modalidades devastadoras do "retomo no real" da pulsão ameaçam a vida social da pessoa que sofre, que a prática coletiva da instituição se estabelece e não em nome de uma terapêutica somente. Cabe lembrar que, para muitas crianças atendidas no Lugar de Vida, o lugar de tratamento e as instituições são as únicas passibilidades de circulação social. Certas mães dizem com freqüência: "com meu filho, é de casa para o hospital e do hospital para casa, não dá para sair com ele para passear, os autros olham, dá vergonha, dá trabalho, é insuportável" . No Lugar de Vida, as passeios a locais públicos configuram uma possibilidade divertida e prazerosa de inclusão e circulação social de nossas crianças atendidas bem como um dispositivo de tratamento institucional que incide sobre a criança, seus pais, os interventores e a sociedade. Será que pensar em inclusão social seja também transformar em suportável e possível o que é diferente e o que incomoda e dá trabalho a toobs?

Com relação à posição dos profissionais envolvidos, Zenoni afirma que estes se deparam com o real de uma questão clínica que passa a ser comparti lhada, mas cada um deve contribuir para presentificar uma figura do Outro que permita ao sujeito ter um lugar sem a ruptura da passagem ao ato, tão freqüente na clínica das psicoses. "Dizer não ao gozo do Outro não implica encamar a lei ou a função patema, nem suprimir toda regra ou toob interdito. Implica, sobretudo, presentificar um autro que seja ele mesmo regulado, enunciar ou lembrar uma regra que regulamente o 
próprio Outro, seja ele o conjunto ou um membro da equipe, até mesmo inventar a regra que permita considerar a exceção" (2002, p. 11) .

Em uma supervisão institucional mais recente, Jerusalinsky, em 2004, afirmou: "Na psiquiatria tradicional, as intervençães são tomadas como normas, regras, como atos mesmo de cura. Para a psicanálise, o que sustenta a cura na neurose é a livre errância da transferência. Mas quando se trata da psicose, estamos na ordem da carne dura, do corpo mesmo, é outra coisa. O princípio analítico que deveria orientar a ara para o anal ista que se propõe tratar a psicose éo se deixar fazer, mesmo que para isso implique em alguns momentos em se deixar bater, se deixar ser cuspido, essa é a condição mínima para que o ato de cura analítico na clínica das psicoses passa se dar. As regras são diferentes de princípios". Acrescentamas aqui que qualquer um pode determinar regras (o que vemos qperar em tantas instituições) , mas só um sujeito pode se fazer ordenar pelo que é da ordem da determinação significante, do Simbólico, talvez nesse campo é que estejam os princípios e em que uma "exceção à regra" possa fazer toob o sentidb.

\section{A LINGUAGEM - 0 "YOLANDÊS" - O TRAÇO, UMA POSSIBILIDADE DE ESCRITA?}

Diferentemente de palavras que "escapam", que irrompem, as palavras que $Y$. tem vocalizadb atualmen- te parecem estar começando a ser incorporadas em um outro registro, mesmo que precariamente. E, além de estarem sendo usadas apropriadamente num contexto, estão sendo apropriadas por ela. Evidentemente, ainda ocorrem muitas sonoplastias (assim nomeei sua fala característica) , mas a apropriação de Y. dessas palavras proferidas e sua utilização na rara e fortuita comunicação com o outro merecem atenção. Ainda que fragilmente sustentadas, parecem ser da ordem de algum desejo, desejo muitas vezes imperativo, o que toma as situaçães também muitas vezes dismrnptivas tanto para ela quanto para o outro, embora Y. busque de maneira falhada enlaçá-1o. Acreditamos que Y. está na linguagem, mas não dispõe de significantes suficientes para sustentar uma cadeia maior. A extensão é pequena e, na falta deles, o que lhe resta é o próprio corpo. Cabe pensarmos se mesmo diante de uma linguagem peculiarmente tecida poderia se sustentar uma rede maior, um discurso? Convidamos as leitores a pensarem conosco.

Há outras doservações recentíssimas que são dignas de nota. Tratase do início de traças de escrita que Y. tem se empenhado em fazer no registro dabiblicteca, pedindb a ajuda da mão do outro, registro que não consiste em um traço qualquer, pois se trata de deixar num cartão a marca de uma escolha e a marca, mesmo que fragilmente traçada, apostamos dizer, de seu nome.

As mudanças observadas em $Y$. e a maior flexibilidade na relação com o Outro, fizeram-nos apostar também em sua inclusão escolar. Desde 
o início de 2004, Y. freqüenta a $1^{a}$ série do ensino fundamental públi$\infty$, não sem dificuldades certamente, mas agora recebe também o lugar de aluna, colocando a mochila sozinha nas costas e puxando a mão da mãe para irem à escola. Podemos pensar que uma aposta simbólica demova o que anteriormente havia sido atestado e registrado em um relatório médico "criança sem condições de freqüentar escola normal" .

\section{A ADOLESCENNCIA E AS IRRUPÇÕES DO REAL}

No corpo de menina que se transforma em corpo de moça, em seus dez anos recém completados, chega-Ihe a menarca. Y. não passa alheia a essas mudanças e tem se utilizado do corpo de outras meninas do grupo para explorar e indagar de algum modo o seu: abraça, toca, aperta, agarra, alisa os cabelos, quer ver o conpo das meninas e, em seguida, vai para o espelho para ver seus próprios peitos, barriga e cabelos, movimento inverso do início do tratamento, em que somente a partir do espelho conseguia ir em direção ao corpo do outro. Os mimetismos também têm sido comuns, chora quando C. chora; pula e ri quando W. pula, porém não se trata de mimetismos tão adesivos e automáticos, pois em vários momentos busca provocar algo diferente no outro e se põe a esperar a reação desejada, seja de choro, de riso ou de surpresa. Há uma certa intencionalidade em seus atos e uma expectativa de resposta do autro. 
Em entrevista com a mãe, verificou-se que esta investigação conporal de Y. também tem ocorrido no corpo da mãe, nos momentos em que tomam banho juntas. M. conta que Y. a tem observado muito e está muito "grudada" nela ultimamente. Fica o tempo todo onde a mãe estiver e chora aas berros em sua ausência. O interesse de Y. en tocar e alisar os cabelos das meninas e profissionais do grupo e o interesse pelo universo feminino é reiterado pela mãe, quando conta que já fez curso de cabeleireira e é ela quem corta e cuida dos cabelos da filha e de todos os familiares.

Podemos pensar que as processos de identificação primária e secundária estão operando em algum nível. Apesar da imagem de seu corpo ser ainda bastante inconsistente, é a partir desse corpo precariamente imaginado que Y. busca identificações no conpo do outro feminino. É de se verificar que, com tão poucas passibilicades simbólicas, essas identificações ocorram freqüentemente na colagem com o corpo do autro, seus colegas de grupo, assim como os adultos interventores são testemunhas disso. Sobre esses aspectos das identificaçães penso que há também muitas questões a serem discutidas sobre o tratamento grupal nesta clínica das psicoses, pois nos deparamos ora com crianças se espellhando, respondendo e se organizandb através do attro colega, ora com momentos de contaminação desagregadora e fenômenos massivos de grupo. De uma forma ou de outra, pensamos que, por meio do estudo do tão citado "caso a caso", da passibilidade de se fazer um diag- 
nóstico diferencial, de estabelecer uma direção de tratamento e precisar as indicações de intervenções, poderão ser bal izados os riscos/benefícios da entrada e permanência de uma criança psicótica em tratamento grupal. Bem como pensarmos ainda se há especificidades nas intervenções grupais, pela via do discurso do autro, e nos atendimentos individuais, em que a transferência com o pequeno autro poderia ser melhor manejada. Não podemos também perder de vista que só no depois, no apréss-coup, é que o sentiob, a significação se dá, não é possível pensar nos benefícios enos efeitos de uma oferta de tratamento sem antes ofertar, sem antes um pouco inventar e arriscar.

As mudanças que a adolescência obrigatoriamente imprime no conpo de Y. vêm, por um lado, possibilititar uma saída imaginária, por meio das identificaçães com o corpo do outro, mas, por outro, trazem à tona com toda força o que é da ordem do corpo-borda, lugar de gozo, para o qual Y. tem sofrivelmente tentado dar algum contorno e algum estofo. Quando a primeira tentativa fracassa, o que the resta são as abjetos e o puro conpo; então o chão e as paredes passam a Ihe dizer o que é sua cabeça, os berros_a sua boca, oxixi_a sua vagina, o líquido derramado em sua roupa - o seu corpo. Em outros momentos, consegue até mesmo prescindir dos próprios objetos e ensimesmada, desconectada, com o olhar distante, se põe a movimentar as mãos estereotipadamente. Laznik (1997) cita sobre o circuito pulsional, "o $2^{\circ}$ tempo pode ser enganador, ele só pode ser considerado auto-erótico se soubermos do $3^{\circ}$ tempo. Sem esse, o Outro não está presente, sem o termo eros, o auto-erotismo passa a ser autismo" .

Jerusalinsky, em 2004, na mesma supervisão institucional citada anteriormente, faz consideraçães acerca da psicose: "A simbolização da qual um psicótico é capaz tem uma extensão muito curta, as representaçães do outro têm pouca variabilidade, ou são representaçães fragmentadas do outro, descontínuas e limitadas. Há uma colagem entre o outro e o Outro e quanto mais parcial é a representação do autro, mais colado ele fica ao pequeno outro. Não dispõe de representações para o que fica além de uma redoma e, se cai no meio delas, está perdido" . No caso de Y., podemas pensar que ela alça ao $3^{\circ}$ tempo da pulsão, há representação de outro, mas, como as amarras simbólicas são tão frágeis, no encontro com o grande outro ela cai o tempo toodo.

\section{INCONCLUSÕES, PORÉM INDAGAÇÕES}

Os movimentos de $\mathrm{Y}$. parecem evidenciar uma construção "capenga", insuficiente para uma arquitetura e alicerces dignos da construção Simbólica, mas trata-se ainda de uma construção em andamento, que evidentemente deveria ter ocorrido mais precocemente como todo alicerce; mas será que, mesmo tardiamente, ainda possa constituir psiquicamente uma criança numa posição discursiva? Será que um tem- 
po já se passou? ou que tipo de construção ela será capaz de sustentar?

A estrutura que a sustenta e a arquitetura psíquica desenhada parece ser tipicamente a de uma psicase, mas que transita desole o registro do Real nas vivências de seu conpo e do corpo do outro em pedaças (esquizofrenicamente sofrível) , à saída autística coma exclusão do Outro, até os momentos em que Y. parece ter acedido a uma organização muito próxima a de uma identificação histérica, muito mais precária e imaginária que simbólica, é certo. Mas será que desta múnima e instável organização ela possa "escapar" da constituição psíquica psicótica propriamente dita? Ela ainda poderá "escolher" um outro destino? No seu tempo cronológico e orgânico da adblescência ou, no seu tempo lógico, a escolha já se deu?

Para finalizar, pelo menos este texto, é evidente que as construçães verificadas no tratamento não se dão de forma linear, pois ainda há a sonoplastia, palavras incompreensíveis, cabeçadas e berros ensurdecedores, restos que, apesar da menor freqüência, ainda insistem em aparecer. Porém, acreditamos que se trata de uma postura ética: ainda podermos apostar que desses restos possam restar menos ainda e da boca enorme da qual antes só saíam vômitos e berros possam também sair mais algumas palavras para nunca deixar calar e ensurdecer, como seus pais, a fala dos que se empenham em escutá-la e tratar dela. Talvez o caso "Yolandamanda" possa, em algum momento, ser rebatizado de "Yoladademanda" , considerando modos diferentes de demandar, assim como modos diferentes de gozar; e de uma criança estranha que não fala como as demais, não se aquieta e não indaga o outro, possa também advir para um Outro uma pequena bailarina ou uma fantasiosa princesa.

Seja da linguagem operante através da fala, da escrita, ou do corpo, nos perguntamos se o Discurso Psicanalítico que conhecemos até então tem conseguido sustentar e abarcar as tão diversos e pecul iares disarrsos himanos. E, voltando para nassa clínica. .. em nossa instituição Lugar de Vida, levando em consideração as diferentes momentos de constituição psíquica das crianças, as dispositivos institucionais que criamos e as intervenções das quais lançamos mão, sustentados por este discurso psicanalítico, o que temos podido alcançar? Até onde podemos esperar e demandar de nossa prática e de nossas crianças?

Diante de tantos discursos, tantas palavras, signos, símbolos e significantes, de tantas retóricas inclusive, não estaríamos também diante de tantos loucos articuladamente falantes? Será que de nossas crianças desprovidas de fala não poderíamos também estar diante de sujeitos loucamente músicos, dançarinos, artistas, equilibristas? 
Dolto, F. (1972) . O caso Dominique. Rio de Janeiro, RJ: Zahar Editores.

Jenusal insky, A. (1990) . "A formação da imagem conporal". In: Escritos da Criança. Porto Alegre, RS: Centro Lydia Coriat, 3 (3) .

Lacan, J. (1949) . "O estádio do espelho como formador da função do eu" . In: Escritos. Rio de Janeiro, RJ: Jorge Zahar, 1998.

(1955) . O seminário sobre "A carta roubada" . In: Escritos. Rio de Janeiro, RJ: Jorge Zahar, 1998.

Lemer, R. (2004). Análise Institucional de uma criança diagnosticada camo Autista. Tese de Doutorado. IPUSP, São Paulo.

Laznik-Penot, M. C. (1994) . "Do fracasso da instauração da imagem do corpo ao fracasso db circuito pulsional: Quandb a alienação faz falta". In: Oque a clínica do autismo pode ensinar aos psicanalistas. Salvador, BA: Ágalma.

(1997) . "Poderíamos pensar numa prevenção da síndrome autística?" In: Palavias em tomo do berço. Salvador, BA: Ágalma.

(2000) . "A voz como primeiro objeto da pulsão oral". In: A voz da sereia: o autismo e os impasses na constituição db sujeito. Salvadbr, BA: Ágalma, 2004.

Lefort, Robert (1991) . "Introdução à jomada de estudos do CEREDA" . Miller, J. (org) . In: A criança no disarso analítico. Rio de Janeiro, RJ: Jorge Zahar.

Lefort, Rosine (1991) . "Introdução à jomada de estudbs do CEREDA". Miller, J. (org.) In: OSL, o sujeito e a psicose. Rio de Janeiro, RJ: Jorge Zahar.

Soler, C. (1997) . Autismo e Paranóia. Artigo redigido a partir das aulas do Seminário da Seção Clínica do Departamento de Psicanálise da Universidade de Paris VIII. Trad. Elisabeth da Rocha Miranda.

Teperman, D. \& Inafuku C. K. (1996) . "Eva, Pandora e Cunumim: a curiosidade eas histórias". In: Estilos da Clínica: Revista sobre a Infância com Problemas, 1 (1) , 78-93.

Zenoni, A. (2002) . Tratamento do autro. Préliminaire. Bnuxelas, Antenne 110, n.3, pg 101-112. Texto traduzidos por Marize L. Guglielmetti.

Recebidb em julho/2004.

Aceito em setembro/2004. 